\title{
A Fast Response-Recovery 3D Graphene Foam Humidity Sensor for User Interaction
}

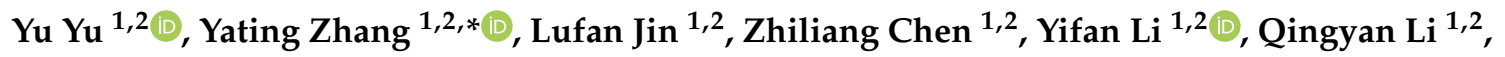 \\ Mingxuan Cao ${ }^{1,2}$, Yongli Che ${ }^{1,2}$, Junbo Yang ${ }^{3}$ and Jianquan Yao ${ }^{1,2}$ \\ 1 Department of Electrical and Electronic Engineering, South University of Science and Technology of China, \\ Shenzhen 518055, China; yuyu1990@tju.edu.cn (Y.Y.); jlfking@tju.edu.cn (L.J.); chenzl@tju.edu.cn (Z.C.); \\ yifanli@tju.edu.cn (Y.L.); liqingyan216@163.com (Q.L.); mingxuancao@tju.edu.cn (M.C.); \\ cheyongli@tju.edu.cn (Y.C.); jqyao@tju.edu.cn (J.Y.) \\ 2 Key Laboratory of Opto-Electronics Information Technology, Ministry of Education, School of Precision \\ Instruments and Opto-Electronics Engineering, Tianjin University, Tianjin 300072, China \\ 3 Center of Material Science, National University of Defense Technology, Changsha 410073, China; \\ yangjunbo008@sohu.com \\ * Correspondence: yating@tju.edu.cn
}

Received: 9 October 2018; Accepted: 3 December 2018; Published: 8 December 2018

\begin{abstract}
Humidity sensors allow electronic devices to convert the water content in the environment into electronical signals by utilizing material properties and transduction techniques. Three-dimensional graphene foam (3DGF) can be exploited in humidity sensors due to its convenient features including low-mass density, large specific surface area, and excellent electrical. In this paper, 3DGF with super permeability to water enables humidity sensors to exhibit a broad relative humidities (RH) range, from $0 \%$ to $85.9 \%$, with a fast response speed (response time: $\sim 89 \mathrm{~ms}$, recovery time: $\sim 189 \mathrm{~ms}$ ). To interpret the physical mechanism behind this, we constructed a 3DGF model decorated with water to calculate the energy structure and we carried out the CASTEP as implemented in Materials Studio 8.0. This can be ascribed to the donor effect, namely, the electronic donation of chemically adsorbed water molecules to the 3DGF surface. Furthermore, this device can be used for user interaction (UI) with unprecedented performance. These high performances support 3DGF as a promising material for humidity sensitive material.
\end{abstract}

Keywords: three-dimensional graphene foams; humidity sensor; fast response; user interaction

\section{Introduction}

Humidity sensors have aroused attention in many fields such as industry, agriculture, and environment [1,2], and medical devices [3]. Generally, they measure humidity through a variety of transduction techniques, including the use of resistive [4,5], capacitive [6], optical fiber [7], and field effect transistors [8,9]. There are also some high precision impedance-frequency transducers using quartz crystals which compensate temperature drift, and have fast response, as investigated by in Matko et al. [10]. In high air humidity measurement there is a problem with response time of the sensors in conventional methods. A solution for this problem is sensors for high air humidity measurement which use open capacitors with very low response time such as is described by Vojko et al. [11].

As an active material for absorbing water molecules, a series of sensing materials including polymers [12], metal oxides [8], carbon nanotubes [13,14], graphene dioxide [15,16], and composites [5,17] have been exploited in humidity sensors. For instance, Zhang et al. [12] described humidity sensors utilizing poly(N-vinyl-2-pyrrolidone) (PVP), poly(vinyl alcohol) (PVA), and hydroxyethyl cellulose (HEC). In particular, after using PVP, the humidity sensors exhibited 
response and recovery times between $11 \%$ and $95 \%$ relative humidity $(\mathrm{RH})$ were about $37 \mathrm{~s}$ and $10 \mathrm{~s}$, respectively. Wang et al. [8] applied a single $\mathrm{SnO}_{2}$ nanowire (NW) to fabricate a humidity sensor, which exhibited a wide sensor RH range (5 85\%), and the response and recovery times were 120 170 s and 20 60 s, respectively. Zhao et al. [15] investigated a humidity sensor based on multi-wall carbon nanotubes where the sensor testing range was about $11 \%$ to $97 \% \mathrm{RH}$, the response time was $45 \mathrm{~s}$, and the recovery time was $15 \mathrm{~s}$. Borini et al. [15] exploited graphene oxide in a humidity sensor and obtained an unprecedented response speed ( $\sim 30 \mathrm{~ms}$ response and recovery times) in a range of $30 \%$ to $70 \%$ RH. Zhang et al. [5] utilized a graphene oxide (GO)/poly(diallyldimethylammonium chloride) (PDDA) nanocomposite film to fabricate a humidity sensor. The humidity sensor exhibited ultrahigh performance over a wide range of $11 \sim 97 \% \mathrm{RH}$, and the recovery time is $125 \mathrm{~s}$ at $11 \% \mathrm{RH}$. Thus, each sensing material has its own advantages and specific conditions of application. In addition, with large surface area to volume ratio, nanomaterials are attractive to fabricate humidity sensors with ultrahigh performance features including high sensitivity and fast response times.

Recently, graphene with three dimensional (3D) architectures, including foams, networks, and gels have been investigated [18-21]. These 3D graphene-based materials not only have the characteristics of graphene, but also have high specific surface area, low density, good mechanical strength and good conductivity [22]. Because of its wide accessibility, easy synthesis and solution processability, high chemical stability and strong adaptability [23,24], 3D graphene foam (3DGF) has attracted great interest in various sensing applications. Meanwhile, 3DGFs are efficient materials for biosensors and gas-sensing devices given their low-mass density, large surface area, good mechanical stability, and high electrical conductivity. Huang and coworkers [25] synthesised 3DGF/CuO nanoflower composites as single-chip independent 3D biosensors for the electrochemical detection of ascorbic acid with outstanding biosensing properties, such as an ultrahigh sensitivity of $2.06 \mathrm{~mA} \mathrm{mM} \mathrm{mm}^{-1} \mathrm{~cm}^{-2}$ to ascorbic acid at a $3 \mathrm{~s}$ response time. Besides that, Yavari et al. [24] used macroscopic 3DGF to fabricate gas detectors with high sensitivity. Generally, these electrical-type 3DGF sensors exhibit high sensitivity due to these properties including an ultrahigh surface area, and its electronic properties. It shows a strong dependence on surface absorbents (including gas molecules), which can change the carrier density of graphene [24]. Therefore, it is necessary to develop a new type of humidity sensor based on 3DGF by utilizing the unique structure and chemical characteristics and avoiding its shortcomings.

In this paper, we fabricate a humidity field effect transistor based on 3DGF and develop test equipment to measure the properties of the device. It exhibits a high performance over a broad $\mathrm{RH}$ range from $0 \%$ to $85.9 \%$, with fast response and recovery times. To interpret the physical mechanism, we construct the 3DGF model decorated with water and apply CASTEP in the Materials Studio software to calculate the energy structure. Herrin, we explore the potential of 3D GF for portable, reliable and low cost humidity sensing applications in the future.

\section{Materials and Methods}

Utilizing a modified Hummers' method, [19-21] graphene oxide, denoted as GO, was synthesized from natural graphite powder by an oxidation reaction. GO ethanol solution $(50 \mathrm{~mL})$ with the concentration of $1 \mathrm{mg} \mathrm{mL}^{-1}$ was sealed in a $100 \mathrm{~mL}$ Teflon-lined autoclave which was then heated up to $180{ }^{\circ} \mathrm{C}$ and held for $12 \mathrm{~h}$. Then the autoclave was cooled naturally to room temperature. The prepared ethanol intermediates were carefully removed from the autoclave by a slow and gradual solvent exchange with water. After the solvent exchange process was completed, the product filled with water was freeze-dried and then dried at $120^{\circ} \mathrm{C}$ for $2 \mathrm{~h}$ in a vacuum oven. Finally, the sample was annealed at $450{ }^{\circ} \mathrm{C}$ in $\mathrm{H}_{2} / \mathrm{Ar}(5 / 95, v / v)$ for $6 \mathrm{~h}$. Finally, the sample was treated in a UV ozone system for $15 \mathrm{~min}$ to obtain the final 3DGF. The infrared spectrum of 3DGF was recorded on a Fourier transform infrared (FTIR) spectrophotometer using potassium bromide $(\mathrm{KBr})$ pellets. Figure 1a shows the FTIR spectra of three-dimensional graphene foam (3DGF)) with water molecules (black line) and dry (red line) conditions. It can be seen that a broad peak at $3436 \mathrm{~cm}^{-1}$ corresponds to the vibration 
due to the stretching and bending of $\mathrm{OH}$ groups present in the water molecules adsorbed by 3DGF. Thus, it was concluded that 3DGF exhibits strong hydrophilicity. Meanwhile, the absorption peaks at 565,1163 , and $1640 \mathrm{~cm}^{-1}$ correspond to the symmetric and antisymmetric stretching vibrations of $\mathrm{C}=\mathrm{O}, \mathrm{C}-\mathrm{O}$, and $\mathrm{C}-\mathrm{C}$ groups for $3 \mathrm{DGF}$, respectively. Figure $1 \mathrm{~b}$ shows the surface morphologies of the 3DGF. Field emission scanning electron microscopy (SEM) images show clear, layered and interconnected three-dimensional uniform graphene sheets. It can be concluded that it forms a spongy porous network structure. [20]. The samples are cut into rectangular slabs (14 $\mathrm{mm} \times 2 \mathrm{~mm})$, and both sides are pasted by copper conductive adhesives on silicon substrates with a size of $14 \mathrm{~mm} \times 14 \mathrm{~mm}$ for electrical contact.
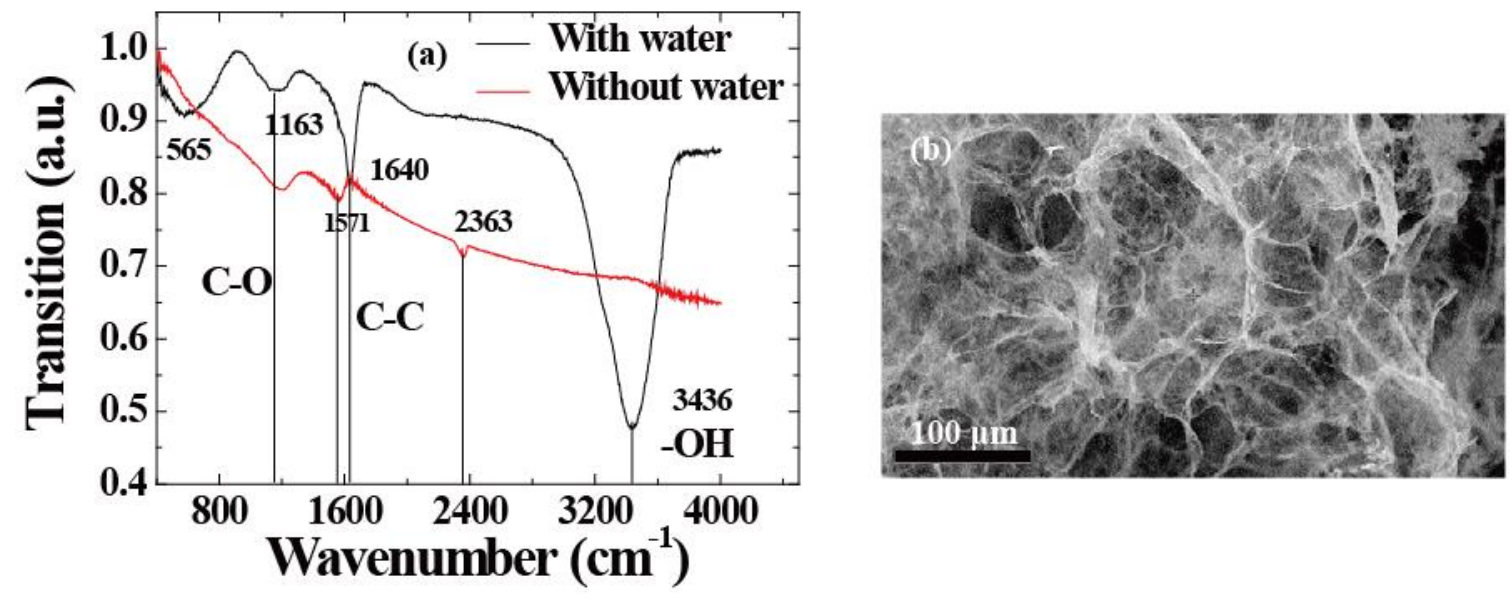

Figure 1. (a) FTIR spectra of 3D graphene with or without water molecule. (b) Field emission scanning electron microscopy (SEM) images of 3DGF.

For humidity sensors, chemical or physical reactions between water molecules and materials induce changes in channel current. External factors including the water concentration, temperature, and operating conditions will impact the performance of the device. For accurate measurements, as shown in Figure 2a, we used a closed box as an experimental chamber to control the humidity. In detail, the water concentrations were controlled by the ratio of saturated water vapor generated by a humidifier to high-purity nitrogen. We assure high quality humidity measurement in different ambient temperature operating conditions in climate chamber as shown in [26]. In order to measure the channel current flowing into the drain electrode $\left(I_{D S}\right)$ [27-29], the source (with ground connection) and drain electrodes were connected with a Keithley 2400 apparatus (Tektronix China Ltd, Shanghai, China). The electrical measurements were also performed with this system, and the RH of the environment was measured by a commercial humidometer. Therefore, as described by Figure $2 b$, the output characteristics of the device were measured under dry and humid conditions. It shows that when the RH level was fixed to $100 \%$, the channel current $\left(I_{D S}\right)$ became lower than the conditions under drying. Meanwhile, the Dirac point shifted towards the positive direction. This donor effect [1] has been ascribed to the donation of electrons from the chemically adsorbed water molecules to the 3DGF. It can be concluded that the water molecules decorated in 3DGF will attract electrons and remain as holes, leading to p-type doping. Furthermore, water molecules decrease the charge mobility of 3D graphene, leading to lower currents. Through swelling or the 2D capillary effect $[7,15,24]$, the dielectric constant will increase and the resistance decrease after adsorbing water molecules (confirmed using FTIR, as shown in Figure 1a). At the same time, the space charge polarization effect can be enhanced by adsorbing more water molecules, leading to the rapid diffusion of 3DGF and the formation of protons between hydroxyl groups. [6]. To investigate the mechanism, band energy of graphene decorating with water molecule was theoretically simulated by density functional theory (DFT) in the Material Studio 8.0 software (Neotrident Technology Ltd. Beijing, China). Simply speaking, graphene is simulated by plane wave program implemented in CASTEP. Considering the single and double supercells $(2 \times 1 \times 1$ 
allowing edge reconstruction) under GGA-PBE with $9 \times 1 \times 1$ k-points Monkhorst-Pack point grid and $500 \mathrm{eV}$ plane wave base truncation, the graphene is simulated by plane wave program with basis cutoff of $500 \mathrm{eV}$. The geometry was optimized until the total energy reached $2 \times 10^{-5} \mathrm{eV} /$ atom and the maximum force acting on each atom is less than $0.05 \mathrm{eV} / \AA$. For the 3D graphene foam and 3D graphene foam adding water molecule calculations, the CASTEP plane wave code was used under GGA-PBE considering a Monkhorst-Pack grid with $9 \times 9 \times 1$ k-points and a plane wave basis cutoff of $500 \mathrm{eV}$; optimizing the geometry until the total energy reaches $2 \times 10^{-5} \mathrm{eV} /$ atom and the maximum force per atom exhibits values less than $0.05 \mathrm{eV} / \AA[30,31]$.

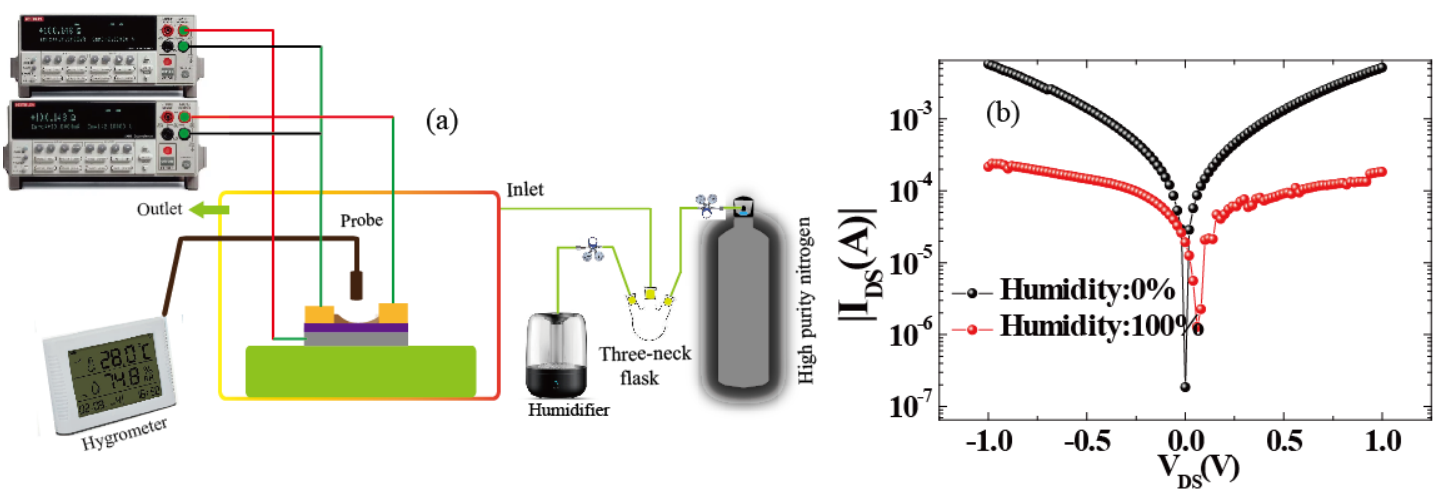

Figure 2. (a) Testing equipment used for the electrical characterization of 3DGF humidity sensors.

(b) Output characteristic of the device decorated with or without water molecules.

\section{Results and Discussion}

Furthermore, the humidity-sensing performance of the 3DGF sensors exposed to different $\mathrm{RH}$ levels $(0 \%, 10.0 \%, 19.9 \%, 30.3 \%, 44.5 \%, 51.4 \%, 57.1 \%, 60.3 \%, 66.4 \%, 70.5 \%, 75.2 \%, 80.2 \%$, and $85.9 \% \mathrm{RH})$ are presented in Figure 3a. In a closed air-tight box, the humidity sensors were measured by different $\mathrm{RH}$ values ranging from 0 to $85.9 \%$. It can be seen that as the $\mathrm{RH}$ level increased, the obtained channel currents of the sensor reduced monotonically. To consider the real-time response and recovery times of the devices, the time-dependent response and recovery curves of the device to $85.9 \% \mathrm{RH}$ are plotted in Figure 3b. The time taken by a sensor to achieve $85 \%$ RH of the total channel current was defined as the response or recovery time. The response and recovery times of the sensor were approximately $89 \mathrm{~ms}$ and $189 \mathrm{~ms}$, respectively. Additionally, our humidity sensors exhibited reproducibility and long-term stability. Professionally, the hysteresis value is a vital parameter for humidity sensors as it determines the maximum time lag between the response time (adsorption process) and recovery time (desorption process). With respect to the water content in the environment, the hysteresis effect is defined by the difference between the resistances. In particular, for a perfect humidity sensor, the hysteresis value should be as small as possible or can even be negligible.

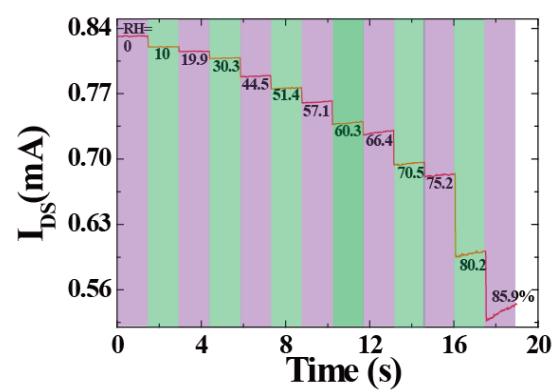

(a)

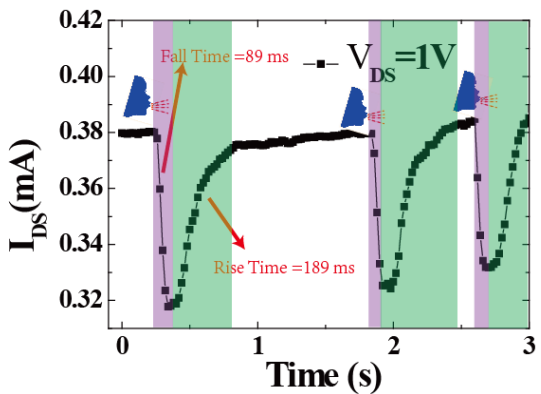

(b)

Figure 3. (a) Channel current response measurement of the 3DGF humidity sensor with varying different RH. (b) Response and recovery times of the device at $85 \% \mathrm{RH}$ and the drain voltage was fixed at $1 \mathrm{~V}$. 
Table 1 compares the different characteristics of graphene-type humidity sensors including the response/recovery time, fabrication method, and sensitivity range. It was observed that the3DGF sensor exhibited broad sensitivity and rapid response and recovery rates.

Table 1. Comparison of different reported humidity sensors with graphene series materials.

\begin{tabular}{cccc}
\hline Reference & Material & Sensing Range & Response/Recovery Time \\
\hline Smith [30] & Graphene & $1-96 \%$ & $0.6 \mathrm{~s} / 0.4 \mathrm{~s}$ \\
Ghosh [32] & Graphene & $4-84 \%$ & $180 \mathrm{~s} / 180 \mathrm{~s}$ \\
Cai [33] & reduced graphene oxide (rGO)/graphene oxide (GO) $/ \mathrm{rGO}$ & $6.3-100 \%$ & $1.9 \mathrm{~s} / 3.9 \mathrm{~s}$ \\
Zhang [34] & Graphene oxide foam & $2 \mathrm{~s} / 10 \mathrm{~s}$ \\
Trung [35] & rGO-polyurethane composites & $10-92 \%$ & $3.5 \mathrm{~s} / 7 \mathrm{~s}$ \\
Leng [36] & GO/Nafion composite & $11.3-97.3 \%$ & $100-300 \mathrm{~s} / \mathrm{not} \mathrm{shown}$ \\
Bi [6] & GO & $15-95 \%$ & $10.5 \mathrm{~s} / 41 \mathrm{~s}$ \\
Naik [37] & GO & $30-95 \%$ & $100 \mathrm{~s} / \mathrm{not} \mathrm{shown}$ \\
Yu [38] & GO/poly (sodium 4-styrenesulfonate) (PSS) composite & $60 \mathrm{~s} / 50 \mathrm{~s}$ \\
Zhang [5] & rGO/poly(diallylimethyammonium chloride) PDDA composite & $20-80 \%$ & $11-97 \%$ \\
Guo [39] & rGO & $10-95 \%$ & $508 \mathrm{~s} / 94 \mathrm{~s}$ \\
This work & 3DGF & $0-85.9 \%$ & $89 \mathrm{~s}$ \\
\hline
\end{tabular}

It can be seen that our devices showed good uniformity. Quantitatively, the effect of relative humidity on the device is depicted in Figure 4. Figure 4a describes the relationship between channel current and relative humidity. It can be seen that the relationship showed a decreasing trend with the increase in water humidity. This also showed that the channel current $\left(I_{D S}\right)$ decreased more rapidly as relative humidity increased. To characterize the performance of the humidity sensor, the sensitivity $(S)$ of the device was defined by Equation (1) $[4,5,30,40]$ :

$$
S=\frac{\left|I_{w e t}-I_{d r y}\right|}{I_{d r y} \mathrm{RH}} \times 100
$$

where $I_{\text {wet }}$ and $I_{d r y}$ represent the channel current of the device under wet and dry conditions $(\mathrm{RH}=0 \%)$, respectively. As shown in Figure $4 b$, the sensitivity increased rapidly as $\mathrm{RH}$ increased. Due to its perfect performance, including its ultrafast response/recovery rate, our humidity sensors can be used for breathing monitoring or for developing new user interfaces (UIs). Figure 3b presents the ability of a 3DGF sensor to monitor human breathing. In particular, during the user's speech, the ultrafast humidity sensor allowed the capture of fine features due to moisture modulation. Therefore, the 3DGF ultra-fast RH sensor can be used to identify different whistles, which can make use of low-cost and low-power sensors for user authentication.
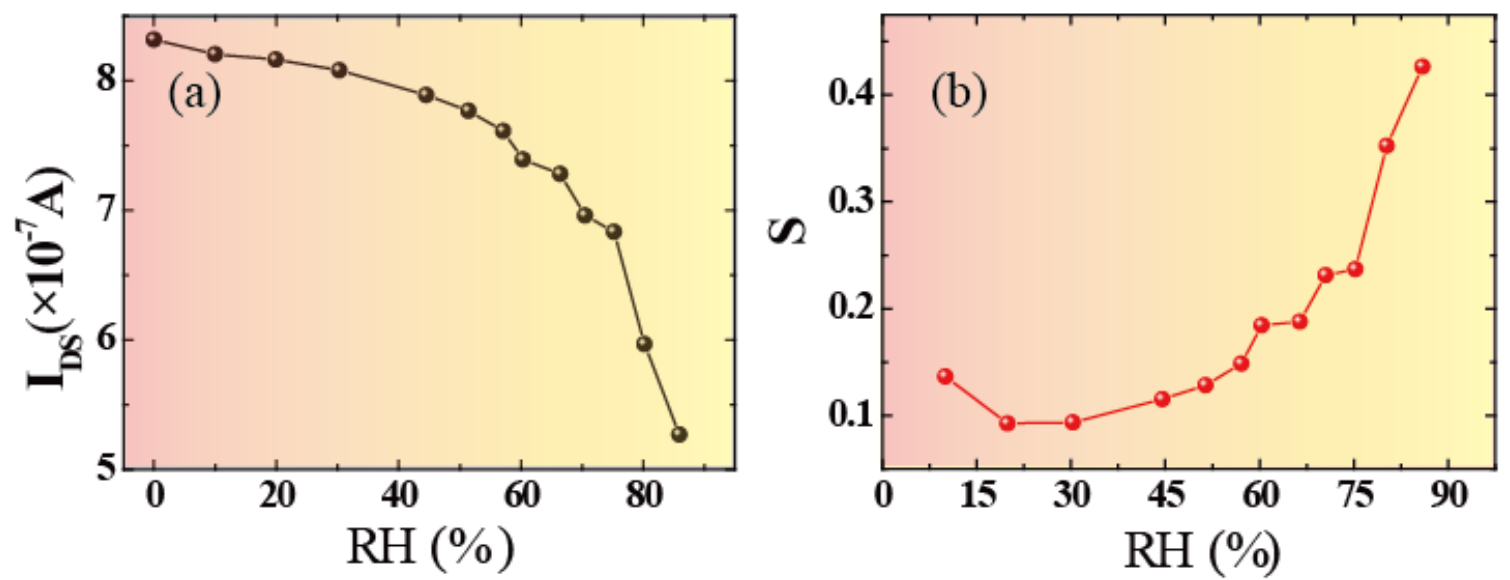

Figure 4. Relative humidity effect on the device performance. (a) Channel currents $\left(I_{D S}\right)$ with the relationship of RH (b) The variation in sensitivity of the device for different RH values. 
A schematic model of humidity sensing at a 3DGF film is shown in Figure 5a. To investigate its mechanism, the band energy of graphene decorated with water molecules was theoretically simulated by density functional theory (DFT) in the Material Studio 8.0 software. As shown in Figure $5 \mathrm{~b}$, conductivity and valence are at $\mathrm{K}$ Brillouin point, which makes the material a direct bandgap semiconductor. The direct band gap at the $\mathrm{K}$ point was $\sim 0.172 \mathrm{eV}$, as shown in Figure $5 \mathrm{c}$. This can be ascribed to the donor effect [3] attributed to the donation of electrons from the chemically adsorbed water molecules to the 3DGF surface. The water molecules decorated in 3DGF will attract electrons. Simply, water molecules open the band gap of 3DGF. Meanwhile, electron density will decrease and the conduction level will rise, leading to the formation of band energy.
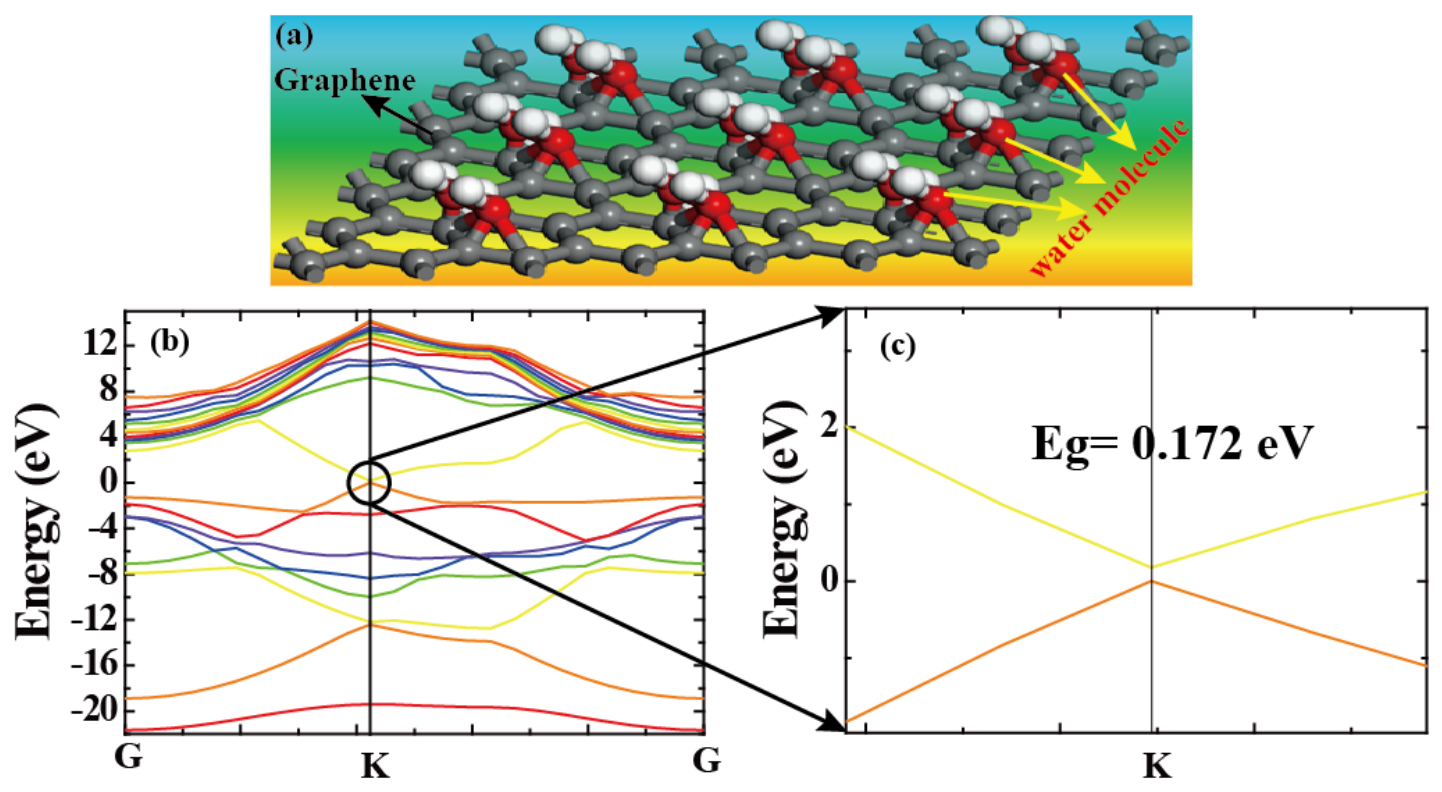

Figure 5. (a) The bonding mechanism between the graphene and water molecules. (b) The electronic band structure of graphene decorated with water. (c) The energy gap at the K point location.

\section{Conclusions}

In summary, a three-dimensional graphene foam (3DGF) exhibiting super permeability to water was exploited in humidity sensors, enabling a humidity sensor with a broad range of $\% \mathrm{RH}$ values and unprecedented response speed (response time: $\sim 89 \mathrm{~ms}$, recovery time: $\sim 189 \mathrm{~ms}$ ). The ultra-fast response speed of these sensors enables us to observe the regulation of moisture in a user's breath. We constructed the 3DGF model decorated with water molecules theoretically and conducted the CASTEP as implemented in Materials Studio to calculate the energy structure. This allows sensors to be used in a variety of applications, such as humidity sensing, which we have experimentally verified with a cheap and easily available identification system. In addition, for different 3D materials, such as $3 \mathrm{D}$ transition metal dihalogenated hydrocarbons, ultra-thin nanoporous membranes for sensing applications can be realized in the interaction with different vapors and gases, which can be explored.

Author Contributions: Conceptualization, Y.Y. and Y.Z.; methodology, Y.Z.; formal analysis, Y.Y., Z.C., Y.L., L.J., Q.L., Y.C., and M.C; data curation, Y.Y.; writing —original draft preparation, Y.Y.; writing — review and editing, Y.Y.; supervision, Y.Z. and J.Y. (Junbo Yang); project administration, Y.Z. and J.Y. (Jianquan Yao); funding acquisition, J.Y. (Jianquan Yao).

Funding: This work was supported by the National Natural Science Foundation of China (Nos. 61675147, 61605141 and 61735010), Basic Research Program of Shenzhen (JCYJ201704121544474699) and Wenzhou City Governmetal Public Industrial Technology Project (G20160014).

Acknowledgments: We thank Yongshen Chen group in Nankai University, which he provides three dimensional graphene foam.

Conflicts of Interest: The authors declare no conflict of interest. 


\section{References}

1. Traversa, E. Ceramic sensors for humidity detection: The state-of-the-art and future developments. Sens. Actuators B Chem. 1995, 23, 135-156. [CrossRef]

2. Chu, J.; Peng, X.; Feng, P.; Sheng, Y.; Zhang, J. Study of humidity sensors based on nanostructured carbon films produced by physical vapor deposition. Sens. Actuators B Chem. 2013, 178, 508-513. [CrossRef]

3. Chen, Z.; Lu, C. Humidity Sensors: A Review of Materials and Mechanisms. Sens. Lett. 2005, 3, $274-295$. [CrossRef]

4. Mogera, U.; Sagade, A.A.; George, S.J.; Kulkarni, G.U. Ultrafast response humidity sensor using supramolecular nanofibre and its application in monitoring breath humidity and flow. Sci. Rep. 2014, 4, 4103. [CrossRef] [PubMed]

5. Zhang, D.; Tong, J.; Xia, B. Humidity-sensing properties of chemically reduced graphene oxide/polymer nanocomposite film sensor based on layer-by-layer nano self-assembly. Sens. Actuators B Chem 2014, 197, 66-72. [CrossRef]

6. Bi, H.; Yin, K.; Xie, X.; Ji, J.; Wan, S.; Sun, L.; Terrones, M.; Dresselhaus, M.S. Ultrahigh humidity sensitivity of graphene oxide. Sci. Rep. 2013, 3, 2714. [CrossRef] [PubMed]

7. Wong, W.C.; Chan, C.C.; Chen, L.H.; Li, T.; Lee, K.X.; Leong, K.C. Polyvinyl alcohol coated photonic crystal optical fiber sensor for humidity measurement. Sens. Actuators B Chem. 2012, 174, 563-569. [CrossRef]

8. Kuang, Q.; Lao, C.; Wang, Z.L.; Xie, Z.; Zheng, L. High-Sensitivity Humidity Sensor Based on a Single $\mathrm{SnO}_{2}$ Nanowire. J. Am. Chem. Soc. 2007, 129, 6070-6071. [CrossRef]

9. Hu, P.; Zhang, J.; Li, L.; Wang, Z.; O’Neill, W.; Estrela, P. Carbon nanostructure-based field-effect transistors for label-free chemical/biological sensors. Sensors 2010, 10, 5133-5159. [CrossRef]

10. Vojko, M. Next generation AT-cut quartz crystal sensing devices. Sensors 2011, 11, 4474-4482.

11. Matko, V.; Donlagic, D. Sensor for high-air-humidity measurement. Sens. Actuators A Phys. 1997, 61, 331-334. [CrossRef]

12. Fei, T.; Zhao, H.; Jiang, K.; Zhou, X.; Zhang, T. Polymeric humidity sensors with nonlinear response: Properties and mechanism investigation. J. Appl. Polym. Sci. 2013, 130, 2056-2061. [CrossRef]

13. Chen, W.P.; Zhao, Z.G.; Liu, X.W.; Zhang, Z.X.; Suo, C.G. A Capacitive Humidity Sensor Based on Multi-Wall Carbon Nanotubes (MWCNTs). Sensors 2009, 9, 7431-7444. [CrossRef] [PubMed]

14. Han, J.-W.; Kim, B.; Li, J.; Meyyappan, M. A carbon nanotube based ammonia sensor on cellulose paper. RSC Adv. 2014, 4, 549-553. [CrossRef]

15. Borini, S.; White, R.; Wei, D.; Astley, M.; Haque, S.; Spigone, E.; Harris, N.; Kivioja, J.; Ryhänen, T. Ultrafast Graphene Oxide Humidity Sensors. ACS Nano 2013, 7, 11166-11173. [CrossRef] [PubMed]

16. Zhao, X.; Long, Y.; Yang, T.; Li, J.; Zhu, H. Simultaneous High Sensitivity Sensing of Temperature and Humidity with Graphene Woven Fabrics. ACS Appl. Mater. Interfaces 2017, 9, 30171-30176. [CrossRef] [PubMed]

17. Zhang, D.; Tong, J.; Xia, B.; Xue, Q. Ultrahigh performance humidity sensor based on layer-by-layer self-assembly of graphene oxide/polyelectrolyte nanocomposite film. Sens. Actuators B Chem. 2014, 203, 263-270. [CrossRef]

18. Ma, Y.; Chen, Y. Three-dimensional graphene networks: Synthesis, properties and applications. Natl. Sci. Rev. 2015, 2, 40-53. [CrossRef]

19. Wu, Y.; Yi, N.; Huang, L.; Zhang, T.; Fang, S.; Chang, H.; Li, N.; Oh, J.; Lee, J.A.; Kozlov, M.; et al. Three-dimensionally bonded spongy graphene material with super compressive elasticity and near-zero Poisson's ratio. Nat. Commun. 2015, 6, 6141. [CrossRef]

20. Zhang, T.; Chang, H.; Wu, Y.; Xiao, P.; Yi, N.; Lu, Y.; Ma, Y.; Huang, Y.; Zhao, K.; Yan, X.-Q.; et al. Macroscopic and direct light propulsion of bulk graphene material. Nat. Photonics 2015, 9, 471-476. [CrossRef]

21. Chang, H.; Qin, J.; Xiao, P.; Yang, Y.; Zhang, T.; Ma, Y.; Huang, Y.; Chen, Y. Highly Reversible and Recyclable Absorption under Both Hydrophobic and Hydrophilic Conditions using a Reduced Bulk Graphene Oxide Material. Adv. Mater. 2016, 28, 3504-3509. [CrossRef]

22. Cao, X.; Yin, Z.; Zhang, H. Three-dimensional graphene materials: Preparation, structures and application in supercapacitors. Energy Environ. Sci. 2014, 7, 1850-1865. [CrossRef] 
23. Chabot, V.; Higgins, D.; Yu, A.; Xiao, X.; Chen, Z.; Zhang, J. A review of graphene and graphene oxide sponge: Material synthesis and applications to energy and the environment. Energy Environ. Sci. 2014, 7, 1564-1596. [CrossRef]

24. Yavari, F.; Chen, Z.; Thomas, A.V.; Ren, W.; Cheng, H.M.; Koratkar, N. High sensitivity gas detection using a macroscopic three-dimensional graphene foam network. Sci. Rep. 2011, 1, 166. [CrossRef]

25. Ma, Y.; Zhao, M.; Cai, B.; Wang, W.; Ye, Z.; Huang, J. 3D graphene foams decorated by CuO nanoflowers for ultrasensitive ascorbic acid detection. Biosens. Bioelectron. 2014, 59, 384-388. [CrossRef] [PubMed]

26. Brezovec, B.; Matko, V. Software and Equipment for Remote Testing of Sensors. Sensors 2007, 7, $1306-1316$. [CrossRef]

27. Yu, Y.; Zhang, Y.; Zhang, Z.; Zhang, H.; Song, X.; Cao, M.; Che, Y.; Dai, H.; Yang, J.; Wang, J.; et al. Broadband Phototransistor Based on $\mathrm{CH}_{3} \mathrm{NH}_{3} \mathrm{PbI}_{3}$ Perovskite and PbSe Quantum Dot Heterojunction. J. Phys. Chem. Lett. 2017, 8, 445-451. [CrossRef]

28. Yu, Y.; Zhang, Y.; Song, X.; Zhang, H.; Cao, M.; Che, Y.; Dai, H.; Yang, J.; Zhang, H.; Yao, J. High Performances for Solution-Pocessed 0D-0D Heterojunction Phototransistors. Adv. Opt. Mater. 2017, 5, 1700565. [CrossRef]

29. Yu, Y.; Zhang, Y.; Song, X.; Zhang, H.; Cao, M.; Che, Y.; Dai, H.; Yang, J.; Zhang, H.; Yao, J. PbS-Decorated $\mathrm{WS}_{2}$ Phototransistors with Fast Response. ACS Photonics 2017, 4, 950-956. [CrossRef]

30. Smith, A.D.; Elgammal, K.; Niklaus, F.; Delin, A.; Fischer, A.C.; Vaziri, S.; Forsberg, F.; Rasander, M.; Hugosson, H.; Bergqvist, L.; et al. Resistive graphene humidity sensors with rapid and direct electrical readout. Nanoscale 2015, 7, 19099-19109. [CrossRef]

31. Gutierrez, H.R.; Perea-Lopez, N.; Elias, A.L.; Berkdemir, A.; Wang, B.; Lv, R.; Lopez-Urias, F.; Crespi, V.H.; Terrones, H.; Terrones, M. Extraordinary room-temperature photoluminescence in triangular $\mathrm{WS}_{2}$ monolayers. Nano Lett. 2013, 13, 3447-3454. [CrossRef] [PubMed]

32. Ghosh, A.; Late, D.J.; Panchakarla, L.S.; Govindaraj, A.; Rao, C.N.R. $\mathrm{NO}_{2}$ and humidity sensing characteristics of few-layer graphenes. J. Exp. Nanosci. 2009, 4, 313-322. [CrossRef]

33. Cai, J.; Lv, C.; Aoyagi, E.; Ogawa, S.; Watanabe, A. Laser Direct Writing of a High-Performance All-Graphene Humidity Sensor Working in a Novel Sensing Mode for Portable Electronics. ACS Appl. Mater. Interfaces 2018, 10, 23987-23996. [CrossRef] [PubMed]

34. Zhang, K.-L.; Hou, Z.-L.; Zhang, B.-X.; Zhao, Q.-L. Highly sensitive humidity sensor based on graphene oxide foam. Appl. Phys. Lett. 2017, 111, 153101. [CrossRef]

35. Trung, T.Q.; Duy, L.T.; Ramasundaram, S.; Lee, N.-E. Transparent, stretchable, and rapid-response humidity sensor for body-attachable wearable electronics. Nano Res. 2017, 10, 2021-2033. [CrossRef]

36. Leng, X.; Luo, D.; Xu, Z.; Wang, F. Modified graphene oxide/Nafion composite humidity sensor and its linear response to the relative humidity. Sens. Actuators B Chem. 2018, 257, 372-381. [CrossRef]

37. Naik, G.; Krishnaswamy, S. Room-Temperature Humidity Sensing Using Graphene Oxide Thin Films. Graphene 2016, 5, 1-13. [CrossRef]

38. Yu, H.W.; Kim, H.K.; Kim, T.; Bae, K.M.; Seo, S.M.; Kim, J.M.; Kang, T.J.; Kim, Y.H. Self-powered humidity sensor based on graphene oxide composite film intercalated by poly(sodium 4-styrenesulfonate). ACS Appl. Mater. Interfaces 2014, 6, 8320-8326. [CrossRef]

39. Guo, L.; Jiang, H.B.; Shao, R.Q.; Zhang, Y.L.; Xie, S.Y.; Wang, J.N.; Li, X.B.; Jiang, F.; Chen, Q.D.; Zhang, T. Two-beam-laser interference mediated reduction, patterning and nanostructuring of graphene oxide for the production of a flexible humidity sensing device. Carbon 2012, 50, 1667-1673. [CrossRef]

40. Zhu, Z.-T.; Mason, J.T.; Dieckmann, R.; Malliaras, G.G. Humidity sensors based on pentacene thin-film transistors. Appl. Phys. Lett. 2002, 81, 4643-4645. [CrossRef]

(C) 2018 by the authors. Licensee MDPI, Basel, Switzerland. This article is an open access article distributed under the terms and conditions of the Creative Commons Attribution (CC BY) license (http:// creativecommons.org/licenses/by/4.0/). 